DOI 10. 18307/2021. 0207

(c) 2021 by Journal of Lake Sciences

\title{
西北干旱区典型水库浮游植物群落结构特征及驱动因子"
}

\author{
杨宋琪 ${ }^{1,2}$, 高兴亮 ${ }^{1}$, 王丽娟 ${ }^{1}$, 祖廷勋 ${ }^{1}$, 王丹霞 ${ }^{1}$, 罗光宏 ${ }^{1 * *}$ \\ ( 1 : 河西学院,甘肃省微藻技术创新中心,甘肃省河西走廊特色资源利用重点实验室,张掖 734000) \\ ( 2 : 西南大学, 三峡库区生态环境教育部重点实验室, 重庆 400715)
}

\begin{abstract}
摘 要: 为了解西北干旱区水库浮游植物群落结构特征, 并进一步探究浮游植物与环境因子之间的相关关系, 于 2017 年 对张掖境内不同分布区域的 8 座典型水库进行为期 4 个季度的采样调查. 结果显示, 调查期间共计检出浮游植物 8 门 106 属 294 种, 其中硅藻门、绿藻门和蓝藻门占比分别为 $48.35 \%$ 、26.64\% 和 $14.47 \%$. 浮游植物密度在 $0.3 \times 10^{4} \sim 4.38 \times 10^{7}$ cells $/ \mathrm{L}$ 之间,夏、秋季较高, 冬季最低, 且随着海拔的降低浮游植物密度呈现显著升高的趋势. Shannon-Wiener 多样性指数、 Simpson 指数、Pielou 均匀度指数和 Margalef 指数年均值分别为 $2.26 、 0.77 、 1.20$ 和 0.86 , 综合浮游植物细胞密度和物种组 成对水质进行评价可知, K1、K2、K3 和 K5 水库为贫营养, K4、K6、K7 和 K8 水库为中营养一富营养. Spearman 相关性分析 和典范对应分析发现, 总氮、电导率、温度和海拔是水库浮游植物密度大小及优势种分布的主要影响因子, 低海拔水库中 细小平裂藻 (Merismopedia minima) 、史密斯微囊藻 (Microcystis smithii) 和惠氏微囊藻 (Microcystis wesenbergii) 等水华蓝藻随 着水温升高而占据绝对优势, 尤其史密斯微囊藻密度在夏季超过水华阈值 $\left(10^{7} \mathrm{cells} / \mathrm{L}\right)$, 值得引起注意.
\end{abstract}

关键词: 水库;浮游植物;群落结构;环境因子;典范对应分析;西北干旱区;张掖

\section{Phytoplankton community structure and driving factors in typical reservoirs of arid region of northwest China*}

\author{
Yang Songqi ${ }^{1,2}$, Gao Xingliang ${ }^{1}$, Wang Lijuan ${ }^{1}$, Zu Tingxun ${ }^{1}$, Wang Danxia ${ }^{1}$ \& Luo Guanghong ${ }^{1 * *}$ \\ (1: Gansu Microalgae Technology Innovation Center, Key Laboratory of Hexi Corridor Resources Utilization of Gansu, Hexi \\ University, Zhangye 734000 , P.R. China) \\ (2: Key Laboratory of Eco-environments in Three Gorges Reservoir Region (Ministry of Education), Southwest University, \\ Chongqing 400715, P.R.China)
}

\begin{abstract}
In order to explore the structural characteristics of phytoplankton community in the main reservoirs in arid climate area, northwest China, and to further study the correlation between phytoplankton and environmental factors, 8 major reservoirs in different distribution areas were surveyed for 4 quarters in 2017. The results reveled that a total 294 species belonging to 8 phyla and 106 genera were identified to be mainly composed of the Bacillariophyta, Chlorophyta and Cyanophyta and in the proportions of $48.35 \%, 26.64 \%$ and $14.47 \%$, respectively. During the survey period, the density of phytoplankton was between $0.3 \times 10^{4}-4.38 \times$ $10^{7}$ cells/L, which was higher in Summer and Autumn than in Winter and Spring, with the existence of a significant increasing trend with decreasing altitude. The Shannon-Wiener diversity index, Simpson index, Pielou evenness index, and Margalef index were $2.26,0.77,1.20$, and 0.86 , respectively. The comprehensive evaluation combining the density of phytoplankton, indicator species and four diversity indices showed that K1, K2, K3 and K5 reservoirs were oligotrophic, while K4, K6, K7 and K8 reservoirs were meso-trophic to trophic. Spearman correlation analysis of phytoplankton density and environmental factors found that phytoplankton density was extremely significantly correlated with total nitrogen ( TN), electrical conductivity (Spc), and altitude, and significantly correlated with temperature, $\mathrm{pH}$, and Sal. Spearman correlation analysis and CCA analysis found that TN, Spc, temperature, and altitude were the main factors influencing phytoplankton density and dominant species distribution in reservoirs. Water-blooming cyanobacteria such as Merismopedia minima, Microcystis smithii and Microcystis wesenbergii had an absolute advantage
\end{abstract}

* 2020-03-10 收稿;2020-06-26 收修改稿.

国家自然科学基金项目 (11665011) 和甘肃省科技计划项目 (18JR2JG001,20JR5RA192,1604FKC090) 联合资助.

** 通信作者;E-mail: 13993693452@163.com. 
in low-altitude reservoir as temperature rise. It was worth noting that the density of Microcystis smithii increased with temperature rise and exceeded the bloom threshold $\left(10^{7}\right.$ cells $\left./ \mathrm{L}\right)$ in Summer.

Keywords: Reservoir; phytoplankton; community structure; environmental factor; canonical correspondence analysis; arid region of northwest China; Zhangye

随着社会和经济的快速发展及人口的增加, 河流、湖泊受到严重污染甚至退化, 人类饮用水、农业灌溉 和水产养殖等越来越依赖水库供水 ${ }^{[1-3]}$, 尤其在自然湖泊较少的干旱地区, 水库发挥着极其重要的功能. 在 水库人为调度过程中, 蓄水排水使其成为高度动态而又复杂的生态系统 ${ }^{[4]}$, 使得水生高等植物等初级生产 者难以得到稳定的水环境进行生长繁殖,致使浮游植物演替成为水库优势类群 ${ }^{[1]}$.

浮游植物是水生态系统初级生产力的主要贡献者, 其组成和多样性变化直接影响水生态系统的结构与 功能, 同时, 因浮游植物对水环境因子变化非常敏感而被广泛应用于湖泊、水库的日常监测中 ${ }^{[5]}$. Han 等研 究发现, 水库因水位波动使浮游植物群落的组成和动态存在较大个体差异 ${ }^{[6]}$, 而氮、磷、溶解氧、温度等亦是 水库浮游植物物种分布及群落演替的主要驱动因子 ${ }^{[7-9]}$. 近年来, 面源污染及生活污水的排放使得水库水体 持续富营养化 ${ }^{[10-11]}$, 水华频发 ${ }^{[12-13]}$, 尤其水华蓝藻大量增殖后释放的藻毒素及异味物质会对农作物、鱼虾贝 类及人体健康造成不可逆的损害 ${ }^{[14-15]}$, 致使水库水生态安全面临严重威胁,生态服务价值丧失 ${ }^{[16]}$.

我国西北干旱地区降雨稀少, 天然湖泊稀缺, 河流径流量小, 因此, 水库水资源在饮用水供应及农业灌 溉方面起着不可替代的作用. 那么面临极端的气候条件和水文过程的影响, 干旱区水库浮游植物组成和丰 度会呈现怎样的特征呢? 以及主导因素是什么? 目前针对西北干旱区水库的类似研究并不多. 为此, 笔者 以位于干旱气候区河西走廊中段的张掖为例, 对其境内分布的主要水库水体环境因子和浮游植物群落结构 进行调查分析, 综合评估水库水质状况, 并进一步明确驱动水库浮游植物物种分布及群落结构变化的关键 环境因子,从而为水库水生态系统精准的监测和评估及管理提供科学依据.

\section{1 研究区域与方法}

\section{1 张掖自然概况及采样点设置}

张掖地处甘肃省河西走廊中段, 属温带大陆性干旱一半干旱气候区, 年均气温 $6 \sim 8^{\circ} \mathrm{C}$, 年均降雨量 $104 \sim$ $328 \mathrm{~mm}$, 且降雨多集中于夏季. 2017 年, 对张掖范围内不同分布区域的 8 座典型水库进行水样的采集 (表 1 , 图 1), 其中高海拔高度大于 $2000 \mathrm{~m}$ 的水库 3 座, 分别为李桥水库、海潮坝水库和鹦鸽嘴水库; 低海拔区域水 库 5 座, 分别为小海子水库、马郡滩水库、刘家深湖水库、马尾湖水库和天城水库, 其中小海子水库为主要的 渔业养殖场,刘家深湖水库为螃蟹养殖区.

表 1 被调查水库的基本信息

Tab.1 Basic information of the reservoirs under investigation

\begin{tabular}{ccccc}
\hline 编号 & 水库 & 经纬度 & 海拔/m & 地理信息 \\
\hline $\mathrm{K} 1$ & 李桥水库 & $38^{\circ} 30^{\prime} 14^{\prime \prime} \mathrm{N}, 101^{\circ} 7^{\prime} 48^{\prime \prime} \mathrm{E}$ & 2193 & 焉支山区 \\
$\mathrm{K} 2$ & 海潮坝水库 & $38^{\circ} 20^{\prime} 9^{\prime \prime} \mathrm{N}, 100^{\circ} 35^{\prime} 31^{\prime \prime} \mathrm{E}$ & 3100 & 祁连山区 \\
$\mathrm{K} 3$ & 婴鸽嘴水库 & $38^{\circ} 57^{\prime} 21^{\prime \prime} \mathrm{N}, 99^{\circ} 52^{\prime} 10^{\prime \prime} \mathrm{E}$ & 2278 & 山区 \\
$\mathrm{K} 4$ & 小海子水库 & $39^{\circ} 17^{\prime} 40^{\prime \prime} \mathrm{N}, 99^{\circ} 53^{\prime} 38^{\prime \prime} \mathrm{E}$ & 1370 & 农业区 \\
$\mathrm{K} 5$ & 马郡滩水库 & $39^{\circ} 3^{\prime} 19^{\prime \prime} \mathrm{N}, 100^{\circ} 11^{\prime} 4^{\prime \prime} \mathrm{E}$ & 1497 & 农业区 \\
$\mathrm{K} 6$ & 刘家深湖水库 & $39^{\circ} 31^{\prime} 55^{\prime \prime} \mathrm{N}, 99^{\circ} 38^{\prime} 15^{\prime \prime} \mathrm{E}$ & 1330 & 盐碱地一农业区 \\
$\mathrm{K} 7$ & 马尾湖水库 & $39^{\circ} 57^{\prime} 7^{\prime \prime} \mathrm{N}, 99^{\circ} 37^{\prime} 55^{\prime \prime} \mathrm{E}$ & 1300 & 荒漠一盐碱地区 \\
$\mathrm{K} 8$ & 天城水库 & $39^{\circ} 42^{\prime} 46^{\prime \prime} \mathrm{N}, 99^{\circ} 33^{\prime} 36^{\prime \prime} \mathrm{E}$ & 1245 & 荒漠一盐碱地区 \\
\hline
\end{tabular}

\section{2 样品的采集与分析}

依据水库面积和周围地理特征在每个水库选择具有代表性的 3 个位点, 分别于 2017 年 3 月、6 月、9 月 中旬和 11 月底采样, 浮游植物定性分析样品用 $25^{\#}$ 浮游生物网采集表层水样并立即用 Lugol 溶液固定保存. 使用 $5 \mathrm{~L}$ 有机玻璃采水器于水体表层 $0.5 \mathrm{~m}$ 深处分采集水样装人 $1 \mathrm{~L}$ 塑料瓶中, 立即加人 $15 \mathrm{~mL} \mathrm{Lugol}$ 溶液 


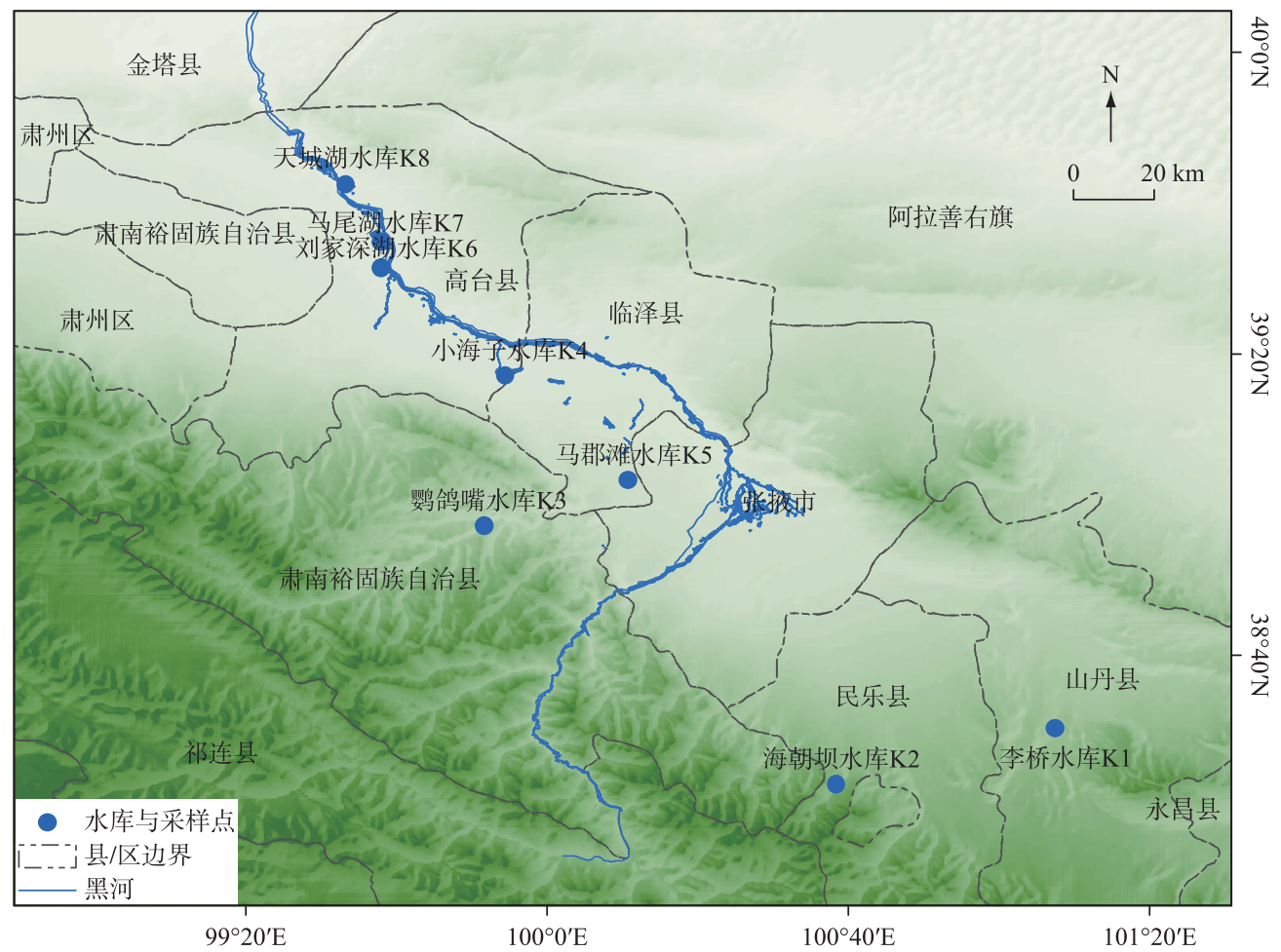

图 1 张掖采样水库位置分布

Fig. 1 Location of the sampling reservoirs in Zhangye

进行固定并摇匀保存, 样品带回实验室静置 $48 \mathrm{~h}$ 后, 用虹吸管移去上清液浓缩至 $30 \mathrm{~mL}$ 进行计数. 计数时, 将浓缩液充分混匀后立即取 $0.1 \mathrm{~mL}$ 于浮游植物计数框计数, 藻类的鉴定参考《中国淡水藻类》、《中国西藏 硅藻》等文献 ${ }^{[17-20]}$.

\section{3 水体理化指标的测定}

现场使用多参数水质分析仪 (美国, YSI ProPlus) 测定水体温度 $\left(\mathrm{T},{ }^{\circ} \mathrm{C}\right.$ ) 、 $\mathrm{pH}$ 、溶解氧 $(\mathrm{DO}, \mathrm{mg} / \mathrm{L})$ 、电导率 $(\mathrm{Spc}, \mu \mathrm{S} / \mathrm{cm})$ 、盐度 $(\mathrm{Sal}, \mathrm{mg} / \mathrm{L})$. 参照文献 $[21]$ 进行总氮 $(\mathrm{TN}, \mathrm{mg} / \mathrm{L})$ 、总磷 $(\mathrm{TP}, \mathrm{mg} / \mathrm{L}) 、$ 硝态氮 $\left(\mathrm{NO}_{3}^{-}-\mathrm{N}\right.$, $\mathrm{mg} / \mathrm{L})$ 、正磷酸盐 $\left(\mathrm{PO}_{4}^{3-}-\mathrm{P}, \mathrm{mg} / \mathrm{L}\right)$ 等水体营养指标测定.

\section{4 多样性指数及优势度的计算}

1.4.1 多样性指数 Shannon-Wiener 多样性指数 $\left(H^{\prime}\right)$ :

$$
H^{\prime}=-\sum_{i=1}^{S} p_{i} \cdot \ln p_{i}
$$

Simpson 指数 $(D)$ :

$$
D=1-\sum_{i=1}^{S} p_{i}^{2}
$$

Pielou 均匀度指数 $(E)$ ：

$$
E=\frac{H}{\ln S}
$$

Margalef 指数 $(d)$ :

$$
d=(S-1) / \ln N
$$

式中, $N$ 为总个体数, $p_{i}$ 为第 $i$ 个种类密度与总密度的比值, $S$ 为藻类的物种数.

1.4.2 优势度 Manaughton 优势度指数 $(Y)$ : 


$$
Y=\frac{N_{i}}{N} f_{i}
$$

式中, $N_{i}$ 为样品中某种藻的数量, $N$ 为采集样品中浮游植物总数量, $f_{i}$ 为样品中某浮游植物出现的频率. 当物 种优势度大于 0.02 时, 该种即为优势种群 ${ }^{[22]}$.

\section{5 数据处理}

聚类分析 (Cluster) 和多维尺度转换排序 (non-metric multidimensional scaling, nMDS) 分析使用 Primer 5 软件. 采用 $\mathrm{R}$ 软件对浮游植物密度及环境因子进行 Spearman 相关性分析和物种与环境的 CCA 分析. 所有物 种在满足出现的频度 $>12.5 \%$ 且物种在至少一个样点的相对密度 $\geqslant 1 \%$ 的基础上 ${ }^{[23]}$, 再选择优势种进行排 序,物种矩阵及环境数据 (除 $\mathrm{pH}$ 值外) 均经过 $\lg (x+1)$ 转换 ${ }^{[24]}$. 对物种信息进行去趋势对应分析 (DCA), 排 序轴梯度长度 (LGA) 均大于 3 , 因此选择基于单峰模型的典范对应分析 (CCA).

\section{2 结果分析}

\section{1 水体理化因子变化}

张掖主要水库水体理化因子见表 2 , 可知水体温度四季差异显著 $(P<0.05)$, 年均值在 $(6.12 \pm 1.59) \sim$ $(16.88 \pm 5.33)^{\circ} \mathrm{C}$ 之间, $\mathrm{K} 2$ 水库因处于祁连山区因而年均温度低于 $10^{\circ} \mathrm{C} . \mathrm{DO}$ 浓度在 $(7.73 \pm 1.23) \sim(11.20 \pm$ $1.34) \mathrm{mg} / \mathrm{L}$ 之间, $\mathrm{pH}$ 在 7.88 $0.18 \sim 8.49 \pm 0.09$ 之间. 受黑河干流下游盐碱地的影响, 不同区域分布水库的 $\mathrm{Spc}$ 和 $\mathrm{Sal}$ 差异显著 $(P<0.05)$, 其中 $\mathrm{K} 8$ 最高, 分别为 $(1768.33 \pm 382.82) \mu \mathrm{S} / \mathrm{cm}$ 和 $(947.49 \pm 197.73) \mathrm{mg} / \mathrm{L}$. 水 体营养盐指标中, 8 座水库 $\mathrm{TN}$ 浓度年均值 $1.73 \mathrm{mg} / \mathrm{L}, \mathrm{K} 4$ 水库最高 $(2.02 \pm 0.11) \mathrm{mg} / \mathrm{L}, \mathrm{K} 2$ 水库最低 ( $1.25 \pm$ $0.07) \mathrm{mg} / \mathrm{L}, \mathrm{NO}_{3}^{-}-\mathrm{N}$ 浓度年均值 $0.87 \mathrm{mg} / \mathrm{L}$, 最高值在 $\mathrm{K} 2$ 水库 $(1.13 \pm 0.04) \mathrm{mg} / \mathrm{L}, \mathrm{K} 7$ 水库最低, 仅为 $(0.57 \pm$ $0.14) \mathrm{mg} / \mathrm{L} ; \mathrm{TP}$ 浓度年均值 $0.086 \mathrm{mg} / \mathrm{L}, \mathrm{K} 4$ 水库最高 $(0.15 \pm 0.02) \mathrm{mg} / \mathrm{L}, \mathrm{K} 2$ 水库最低 $(0.03 \pm 0) \mathrm{mg} / \mathrm{L}, \mathrm{PO}_{4}^{3-}-\mathrm{P}$ 浓度年均值 $0.011 \mathrm{mg} / \mathrm{L}, \mathrm{K} 8$ 水库最高 $(0.022 \pm 0.012) \mathrm{mg} / \mathrm{L}, \mathrm{K} 2$ 水库最低 $(0.005 \pm 0.002) \mathrm{mg} / \mathrm{L}$.

表 2 张掖 8 座典型水库环境因子年均值及变化范围 *

Tab.2 The variations and range of reservoir environmental factors in main eight reservoirs of Zhangye

\begin{tabular}{|c|c|c|c|c|c|c|c|c|}
\hline 环境指标 & $\mathrm{K} 1$ & K2 & $\mathrm{K} 3$ & K4 & K5 & K6 & $\mathrm{K} 7$ & K8 \\
\hline 温度/CC & $\begin{array}{c}11.30 \pm 4.20 \\
(2.00 \sim 21.43)\end{array}$ & $\begin{array}{l}6.12 \pm 1.59 \\
(2.5 \sim 9.87)\end{array}$ & $\begin{array}{c}11.59 \pm 2.71 \\
(5.11 \sim 18.30)\end{array}$ & $\begin{array}{c}13.87 \pm 4.27 \\
(4.00 \sim 23.00)\end{array}$ & $\begin{array}{c}14.28 \pm 4.01 \\
(4.43 \sim 21.90)\end{array}$ & $\begin{array}{c}14.90 \pm 5.10 \\
(1.73 \sim 25.20)\end{array}$ & $\begin{array}{c}16.63 \pm 4.97 \\
(3.97 \sim 26.6)\end{array}$ & $\begin{array}{c}16.88 \pm 5.33 \\
(4.10 \sim 29.57)\end{array}$ \\
\hline 溶解氧 $/(m g / L)$ & $\begin{array}{c}9.92 \pm 0.89 \\
(8.30 \sim 12.00)\end{array}$ & $\begin{array}{l}10.95 \pm 0.82 \\
(8.97 \sim 12.9)\end{array}$ & $\begin{array}{c}9.61 \pm 0.67 \\
(7.80 \sim 10.73)\end{array}$ & $\begin{array}{c}7.73 \pm 1.23 \\
(6.10 \sim 9.50)\end{array}$ & $\begin{array}{c}8.85 \pm 1.07 \\
(7.33 \sim 12.00)\end{array}$ & $\begin{array}{c}9.02 \pm 2.00 \\
5.33 \sim 12.80)\end{array}$ & $\begin{array}{c}9.41 \pm 1.27 \\
(6.67 \sim 12.47)\end{array}$ & $\begin{array}{c}11.20 \pm 1.34 \\
(9.40 \sim 15.13)\end{array}$ \\
\hline $\mathrm{pH}$ & $\begin{array}{c}7.99 \pm 0.18 \\
(7.55 \sim 8.42)\end{array}$ & $\begin{array}{c}7.88 \pm 0.18 \\
(7.68 \sim 8.35)\end{array}$ & $\begin{array}{c}8.17 \pm 0.11 \\
(7.98 \sim 8.47)\end{array}$ & $\begin{array}{c}8.12 \pm .0 .11 \\
(7.90 \sim 8.43)\end{array}$ & $\begin{array}{c}8.19 \pm 0.04 \\
(8.10 \sim 8.26)\end{array}$ & $\begin{array}{c}8.49 \pm 0.09 \\
(8.34 \sim 8.68)\end{array}$ & $\begin{array}{c}8.60 \pm 0.11 \\
(8.41 \sim 8.85)\end{array}$ & $\begin{array}{c}8.47 \pm 0.15 \\
(8.33 \sim 8.85)\end{array}$ \\
\hline 电导率/ $(\mu \mathrm{S} / \mathrm{cm})$ & $\begin{array}{c}597.35 \pm 98.97 \\
(417.33 \sim 879.20)\end{array}$ & $\begin{array}{c}565.26 \pm 74.86 \\
(359.57 \sim 715.20)\end{array}$ & $\begin{array}{c}498.72 \pm 54.73 \\
(349.63 \sim 592.67)\end{array}$ & $\begin{array}{c}1282.75 \pm 172.7 \\
(832.00 \sim 1672.00)\end{array}$ & $\begin{array}{c}604.54 \pm 48.67 \\
(506.97 \sim 721.87)\end{array}$ & $\begin{array}{c}1195.08 \pm 74.05 \\
(981.33 \sim 1323.33)\end{array}$ & $\begin{array}{c}995.50 \pm 51.12 \\
(787.67 \sim 1104.67)\end{array}$ & $\begin{array}{c}1768.33 \pm 382.82 \\
(1119.33 \sim 2866.45)\end{array}$ \\
\hline 盐度 $/(m g / L)$ & $\begin{array}{c}316.67 \pm 36.84 \\
(260.00 \sim 423.33)\end{array}$ & $\begin{array}{c}295.83 \pm 52.50 \\
(173.15 \sim 410.00)\end{array}$ & $\begin{array}{c}298.57 \pm 48.50 \\
(163.00 \sim 390.00)\end{array}$ & $\begin{array}{c}638.00 \pm 88.43 \\
(410.00 \sim 840.00)\end{array}$ & $\begin{array}{c}313.70 \pm 37.63 \\
(263.33 \sim 410.50)\end{array}$ & $\begin{array}{c}608.33 \pm 24.24 \\
(540.00 \sim 653.20)\end{array}$ & $\begin{array}{c}537.50 \pm 41.10 \\
(416.65 \sim 596.67)\end{array}$ & $\begin{array}{c}947.49 \pm 197.73 \\
(556.00 \sim 1483.33)\end{array}$ \\
\hline 总氮/(mg/L) & $\begin{array}{c}1.32 \pm 0.14 \\
(1.07 \sim 1.73)\end{array}$ & $\begin{array}{c}1.25 \pm 0.07 \\
(0.88 \sim 1.44)\end{array}$ & $\begin{array}{c}1.57 \pm 0.10 \\
(1.28 \sim 1.83)\end{array}$ & $\begin{array}{c}2.02 \pm 0.11 \\
(1.72 \sim 2.25)\end{array}$ & $\begin{array}{c}1.83 \pm 0.09 \\
(1.24 \sim 2.18)\end{array}$ & $\begin{array}{c}1.98 \pm 0.17 \\
(1.50 \sim 2.42)\end{array}$ & $\begin{array}{c}1.76 \pm 0.18 \\
(1.21 \sim 2.02)\end{array}$ & $\begin{array}{c}1.81 \pm 0.11 \\
(1.58 \sim 2.45)\end{array}$ \\
\hline 总磷/(mg/L) & $\begin{array}{c}0.063 \pm 0.035 \\
(0.046 \sim 0.010)\end{array}$ & $\begin{array}{c}0.033 \pm 0.003 \\
(0.006 \sim 0.069)\end{array}$ & $\begin{array}{c}0.041 \pm 0.021 \\
(0.009 \sim 0.131)\end{array}$ & $\begin{array}{c}0.152 \pm 0.025 \\
(0.099 \sim 0.178)\end{array}$ & $\begin{array}{c}0.099 \pm 0.034 \\
(0.052 \sim 0.152)\end{array}$ & $\begin{array}{c}0.132 \pm 0.027 \\
(0.078 \sim 0.169)\end{array}$ & $\begin{array}{c}0.092 \pm 0.010 \\
(0.056 \sim 0.131)\end{array}$ & $\begin{array}{c}0.095 \pm 0.031 \\
(0.057 \sim 0.161)\end{array}$ \\
\hline 正磷酸盐/(mg/L) & $\begin{array}{l}0.007 \pm 0.002 \\
(0 \sim 0.008)\end{array}$ & $\begin{array}{c}0.005 \pm 0 \\
(0.001 \sim 0.011)\end{array}$ & $\begin{array}{c}0.008 \pm 0.001 \\
(0.005 \sim 0.010)\end{array}$ & $\begin{array}{c}0.011 \pm 0.003 \\
(0.005 \sim 0.021)\end{array}$ & $\begin{array}{c}0.013 \pm 0.003 \\
(0.008 \sim 0.022)\end{array}$ & $\begin{array}{c}0.009 \pm 0.002 \\
(0.003 \sim 0.012)\end{array}$ & $\begin{array}{c}0.015 \pm 0.004 \\
(0.008 \sim 0.027)\end{array}$ & $\begin{array}{c}0.022 \pm 0.012 \\
(0.016 \sim 0.059)\end{array}$ \\
\hline $\mathrm{N}_{3}^{-}-\mathrm{N} /(\mathrm{mg} / \mathrm{L})$ & $\begin{array}{c}0.96 \pm 0.11 \\
(0.43 \sim 0.99)\end{array}$ & $\begin{array}{c}1.13 \pm 0.04 \\
(0.92 \sim 1.11)\end{array}$ & $\begin{array}{c}1.03 \pm 0.09 \\
(0.80 \sim 1.21)\end{array}$ & $\begin{array}{c}1.37 \pm 0.07 \\
(1.09 \sim 1.41)\end{array}$ & $\begin{array}{c}0.91 \pm 0.06 \\
(0.77 \sim 1.09)\end{array}$ & $\begin{array}{c}0.57 \pm 0.11 \\
(0.21 \sim 0.77)\end{array}$ & $\begin{array}{c}0.45 \pm 0.12 \\
(0.16 \sim 0.73)\end{array}$ & $\begin{array}{c}0.56 \pm 0.12 \\
(0.27 \sim 0.80)\end{array}$ \\
\hline
\end{tabular}

* 数据均为平均值 \pm 标准误, 括号内数据为变化范围.

\section{2 浮游植物群落结构特征}

张掖 8 座典型水库共计检出浮游植物 8 门 106 属 294 种 (表 3 ). 其中硅藻门 36 属 137 种, 占总种类数 
的 $46.59 \%$, 绿藻门 38 属 81 种, 占总种类数的 $27.55 \%$, 蓝藻门 17 属 44 种, 占总种类数的 $14.97 \%$, 甲藻门、隐 藻门、金藻门和黄藻门种类占比共计为 $10.89 \%$. 各水 库检出物种差异较大, 其中 $\mathrm{K} 2$ 和 $\mathrm{K} 3$ 种类数最少, 且 硅藻门种类占比均达到 $65 \%$ 以上; 但 $\mathrm{K} 4 、 \mathrm{~K} 6$ 、 $\mathrm{K} 7$ 和 $\mathrm{K} 8$ 检出物种数量显著增加,均达到 140 种以上, 同时蓝藻 门和绿藻门物种数量比例也相应上升.

\section{3 浮游植物密度大小及优势种}

调查期间张掖 8 座典型水库浮游植物密度范围在 $0.3 \times 10^{4} \sim 4.38 \times 10^{7} \mathrm{cells} / \mathrm{L}$ 之间 (图 2). 前 3 个季度 K6、K7 和 K8 密度均显著高于其他水库 $(P<0.05)$; 而 在冬季, $\mathrm{K} 2$ 和 $\mathrm{K} 4$ 水库藻密度最高. 浮游植物的演替 方面,春季除 $\mathrm{K} 1$ 水库外,各水库优势种以硅藻门种类 为主;夏、秋季, $\mathrm{K} 2$ 和 $\mathrm{K} 3$ 水库为硅藻门种类占优, 但
表 3 张掖 8 座典型水库浮游植物群落结构特征

Tab.3 Phytoplankton community structure in main eight reservoirs of Zhangye

\begin{tabular}{ccccccccccc}
\hline 浮游植物 & $\mathrm{K} 1$ & $\mathrm{~K} 2$ & $\mathrm{~K} 3$ & $\mathrm{~K} 4$ & $\mathrm{~K} 5$ & $\mathrm{~K} 6$ & $\mathrm{~K} 7$ & $\mathrm{~K} 8$ & 总物种数 \\
\hline 蓝藻门 & 10 & 7 & 5 & 21 & 8 & 22 & 29 & 30 & 44 \\
绿藻门 & 25 & 3 & 9 & 48 & 18 & 44 & 51 & 49 & 81 \\
硅藻门 & 62 & 49 & 43 & 71 & 51 & 65 & 84 & 101 & 137 \\
甲藻门 & 6 & 1 & 3 & 5 & 6 & 7 & 7 & 7 & 10 \\
裸藻门 & 7 & 1 & 2 & 7 & 4 & 2 & 6 & 7 & 13 \\
隐藻门 & 3 & 1 & 2 & 3 & 1 & 2 & 3 & 2 & 5 \\
金藻门 & 2 & 0 & 1 & 2 & 1 & 1 & 2 & 3 & 3 \\
黄藻门 & 1 & 0 & 0 & 0 & 1 & 1 & 0 & 1 & 1 \\
合计 & 116 & 62 & 65 & 157 & 90 & 144 & 182 & 200 & 294 \\
\hline
\end{tabular}

$\mathrm{K} 4 、 \mathrm{~K} 6 、 \mathrm{~K} 7$ 和 $\mathrm{K} 8$ 水库蓝藻门种类藻密度急剧增加; 冬季, 随着温度的降低, 各水库硅藻门种类密度均达到 最大.

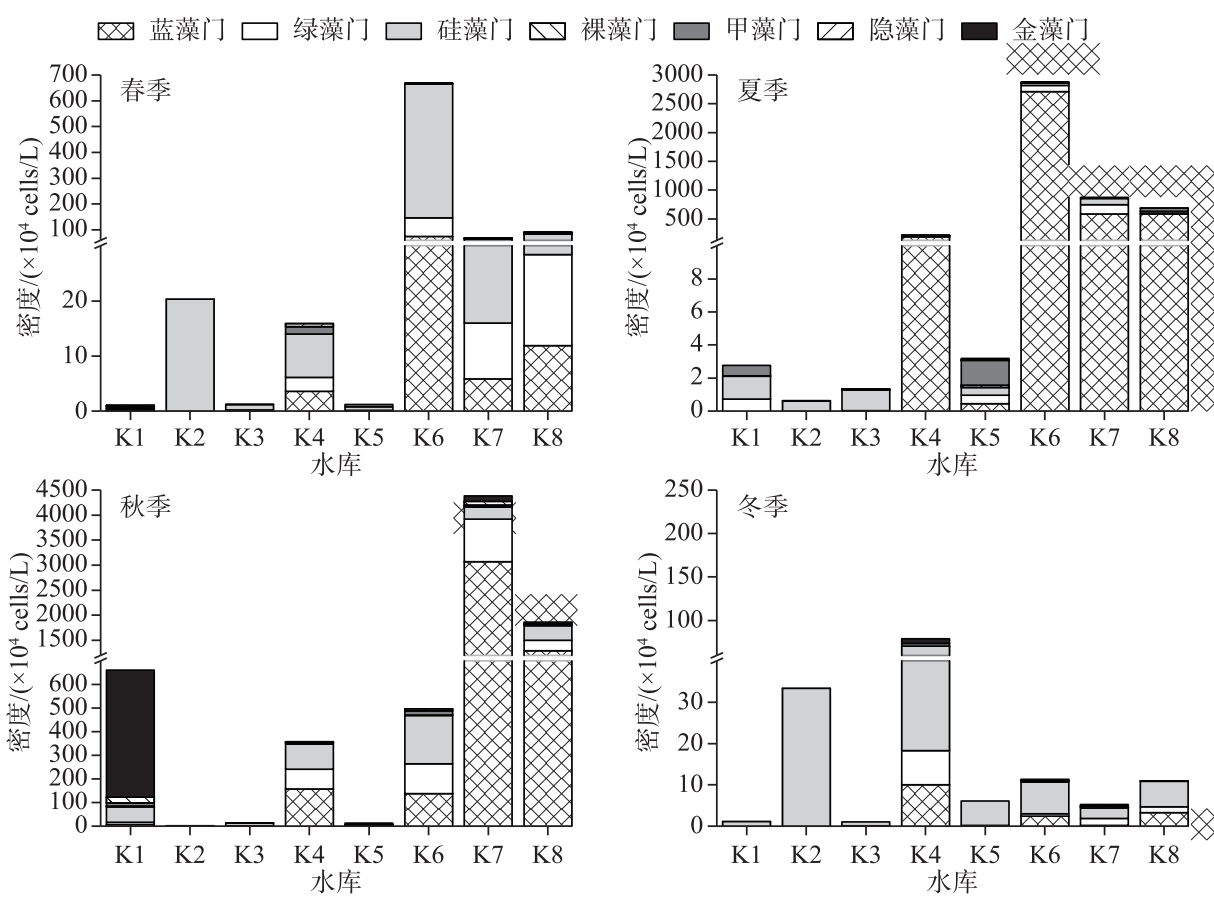

图 2 不同水库各季节浮游植物密度

Fig. 2 Density of phytoplankton of each reservoir in different seasons

优势种分析可知 (表 4), 4 个季节中 K1 水库优势种演替明显, 而 K2 全年则主要以冷水型硅藻门种类微 小曲壳藻 (Achnanthes minutissima) 、延长等片藻细弱变种 (Daitoma elongatum var. tenuis)、弯曲真卵形藻 (Eucocconeis flexella) 和扇形藻 (Meridium sp.) 等占据优势; K3 水库中硅藻门尖针杆藻 (Synedra acus) 在 4 个季度 均占据明显优势; K4 水库在前三个季度优势种主要集中于蓝藻门、绿藻门, 仅在冬季硅藻门的尖针杆藻、尖 端菱形藻 (Nitzschia acula) 占优; K5 水库优势种主要为硅藻门的尖针杆藻、谷皮菱形藻 (Nitzschia palea) 和金 藻门的分歧雉囊藻 (Dinobryon divergens) 等; K6、K7 和 K8 水库则呈现典型的春、冬季硅藻门占优势、夏、秋季 
蓝藻占优势的特点,包括史密斯微囊藻 (Microcystis smithii) 、惠氏微囊藻 (Microcystis wesenbergii)、细小平裂藻 (Merismopedia minima)、假鱼腥藻(Pseudanabaena sp.) 等.

表 4 张掖 8 座典型水库不同季节浮游植物优势种

Tab.4 Dominant species of phytoplankton in each season in eight main reservoirs of Zhangye

\begin{tabular}{|c|c|c|c|c|}
\hline 水库 & 春季 & 夏季 & 秋季 & 冬季 \\
\hline K1 & $\begin{array}{l}\text { 飞燕角甲藻、分歧雉囊藻、 } \\
\text { 卵形隐藻 }\end{array}$ & $\begin{array}{l}\text { 飞燕角甲藻、双对栅藻、扁 } \\
\text { 圆卵形藻 }\end{array}$ & $\begin{array}{l}\text { 谷皮菱形藻、分歧雉囊藻、 } \\
\text { 卵形隐藻 }\end{array}$ & $\begin{array}{l}\text { 尖针杆藻、舟形藻、分歧雉 } \\
\text { 囊藻 }\end{array}$ \\
\hline K2 & $\begin{array}{l}\text { 微小曲壳藻、等片藻、扇 } \\
\text { 形藻 }\end{array}$ & $\begin{array}{l}\text { 微小曲壳藻、扇形藻、尖针 } \\
\text { 杆藻 }\end{array}$ & $\begin{array}{l}\text { 微小曲壳藻、等片藻、舟形 } \\
\text { 藻、弯曲真卵形藻 }\end{array}$ & $\begin{array}{l}\text { 微小曲壳藻、扇形藻、等片 } \\
\text { 藻、小型舟形藻 }\end{array}$ \\
\hline K3 & 尖针杆藻、尖端菱形藻 & $\begin{array}{l}\text { 尖针杆藻、飞燕角甲藻、卵 } \\
\text { 形隐藻 }\end{array}$ & 尖针杆藻、飞燕角甲藻 & 尖针杆藻、尖端菱形藻 \\
\hline K4 & $\begin{array}{l}\text { 席藻、细小平裂藻、四尾 } \\
\text { 栅藻 }\end{array}$ & $\begin{array}{l}\text { 席藻、棒胶藻、四尾栅藻、 } \\
\text { 球衣藻、尖针杆藻 }\end{array}$ & $\begin{array}{l}\text { 史密斯微囊藻、四尾栅藻、 } \\
\text { 球衣藻、谷皮菱形藻、尖针 } \\
\text { 杆藻 }\end{array}$ & $\begin{array}{l}\text { 尖针杆藻、尖端菱形藻、谷 } \\
\text { 皮菱形藻 }\end{array}$ \\
\hline K5 & $\begin{array}{l}\text { 谷皮菱形藻、飞燕角甲藻、 } \\
\text { 分歧雉囊藻 }\end{array}$ & $\begin{array}{l}\text { 尖针杆藻、飞燕角甲藻、纤 } \\
\text { 细裸藻、分歧雉囊藻、 }\end{array}$ & $\begin{array}{l}\text { 尖针杆藻、谷皮菱形藻、库 } \\
\text { 津小环藻 }\end{array}$ & $\begin{array}{l}\text { 尖针杆藻、小环藻、分歧雉 } \\
\text { 囊藻 }\end{array}$ \\
\hline K6 & $\begin{array}{l}\text { 尖端菱形藻、谷皮菱形藻、 } \\
\text { 异极藻 }\end{array}$ & $\begin{array}{l}\text { 史密斯微囊藻、四尾栅藻、 } \\
\text { 球衣藻、放射舟形藻、脆杆 } \\
\text { 藻、尖端菱形藻 }\end{array}$ & $\begin{array}{l}\text { 史密斯微囊藻、惠氏微囊 } \\
\text { 藻、细小平裂藻、棒胶藻、 } \\
\text { 谷皮菱形藻 }\end{array}$ & 尖端菱形藻、谷皮菱形藻 \\
\hline K7 & $\begin{array}{l}\text { 谷皮菱形藻、舟形藻、尖端 } \\
\text { 菱形藻 }\end{array}$ & $\begin{array}{l}\text { 史密斯微囊藻、惠氏微囊 } \\
\text { 藻、束丝藻、细小平裂藻、 } \\
\text { 四尾栅藻 }\end{array}$ & $\begin{array}{l}\text { 细小平裂藻、惠氏微囊藻、 } \\
\text { 史密斯微囊藻、假鱼腥藻、 } \\
\text { 四尾栅藻、球衣藻 }\end{array}$ & $\begin{array}{l}\text { 球衣藻、尖针杆藻、尖端菱 } \\
\text { 形藻、谷皮菱形藻、裸甲藻 }\end{array}$ \\
\hline K8 & $\begin{array}{l}\text { 尖端菱形藻、谷皮菱形藻、 } \\
\text { 库津小环藻 }\end{array}$ & $\begin{array}{l}\text { 史密斯微囊藻、惠氏微囊 } \\
\text { 藻、细小平裂藻、裸甲藻 }\end{array}$ & $\begin{array}{l}\text { 束丝藻、惠氏微囊藻、史密 } \\
\text { 斯微囊藻、尖头藻、假鱼 } \\
\text { 腥藻 }\end{array}$ & $\begin{array}{l}\text { 球衣藻、尖端菱形藻、谷皮 } \\
\text { 菱形藻、舟形藻 }\end{array}$ \\
\hline
\end{tabular}

\section{4 浮游植物多样性指数}

2017 年度, 张掖 8 座水库浮游植物多样性指数 $H^{\prime} 、 D 、 E$ 和 $d$ 年均值分别为 $2.26 、 0.77 、 1.20$ 和 0.86 (表 $5)$. 其中, $\mathrm{K} 7$ 和 $\mathrm{K} 8$ 水库浮游植物的 $H^{\prime} 、 D$ 和 $d$ 均显著高于其他 6 座水库 $(P<0.05), E$ 最高值则出现在 $\mathrm{K} 3$ 水库.

表 5 张掖 8 座典型水库浮游植物多样性指数

Tab.5 The phytoplankton diversity indexes in eight main reservoirs of Zhangye

\begin{tabular}{ccccc}
\hline 水库 & Shannon-Wiener 指数 $\left(H^{\prime}\right)$ & Simpson 指数 $(D)$ & Margalef 指数 $(d)$ & Pielou 均匀度指数 $(E)$ \\
\hline K1 & $2.09 \pm 0.38^{\mathrm{cd}}$ & $0.69 \pm 0.10^{\mathrm{d}}$ & $1.32 \pm 0.19^{\mathrm{ab}}$ & $0.79 \pm 0.16^{\mathrm{cd}}$ \\
K2 & $2.18 \pm 0.18^{\mathrm{cd}}$ & $0.79 \pm 0.03^{\mathrm{b}}$ & $0.79 \pm 0.06^{\mathrm{c}}$ & $0.95 \pm 0.03^{\mathrm{b}}$ \\
K3 & $2.10 \pm 0.05^{\mathrm{cd}}$ & $0.87 \pm 0.03^{\mathrm{a}}$ & $0.72 \pm 0.05^{\mathrm{c}}$ & $1.11 \pm 0.06^{\mathrm{a}}$ \\
K4 & $2.28 \pm 0.21^{\mathrm{bc}}$ & $0.71 \pm 0.08^{\mathrm{cd}}$ & $1.04 \pm 0.09^{\mathrm{bc}}$ & $0.84 \pm 0.06^{\mathrm{c}}$ \\
K5 & $2.26 \pm 0.24^{\mathrm{bc}}$ & $0.75 \pm 0.07^{\mathrm{b}}$ & $1.46 \pm 0.04^{\mathrm{a}}$ & $0.81 \pm 0.09^{\mathrm{c}}$ \\
K6 & $1.97 \pm 0.23^{\mathrm{d}}$ & $0.65 \pm 0.13^{\mathrm{d}}$ & $1.31 \pm 0.10^{\mathrm{ab}}$ & $0.66 \pm 0.14^{\mathrm{e}}$ \\
K7 & $2.82 \pm 0.12^{\mathrm{a}}$ & $0.89 \pm 0.01^{\mathrm{a}}$ & $1.42 \pm 0.16^{\mathrm{a}}$ & $0.94 \pm 0.06^{\mathrm{b}}$ \\
K8 & $2.43 \pm 0.23^{\mathrm{b}}$ & $0.86 \pm 0.04^{\mathrm{a}}$ & $1.56 \pm 0.09^{\mathrm{a}}$ & $0.77 \pm 0.07^{\mathrm{d}}$ \\
\hline
\end{tabular}

\subsection{8 座水库间浮游植物群落相似性分析}

以各位点的浮游植物密度组成原始数据矩阵,运用 Primer 5 进行聚类分析 (Cluster) 和多维尺度转换排 序 (non-metric Multidimensional Scaling,nMDS) 分析, 使得浮游植物群落结构相似性较高的聚成一组. 为更直 观地观察不同水库间浮游植物组成的相似关系, 在 nMDS 序图上勾画了聚类组. 结果表明, 8 个典型水库可 
以分为 3 组, 其中 K2 独立一组, K1 和 K5 为一组, 其余位点为一组 (图 3). 由 nMDS 排序图也可看出, 多维标 度分析结果与聚类分析结果一致.
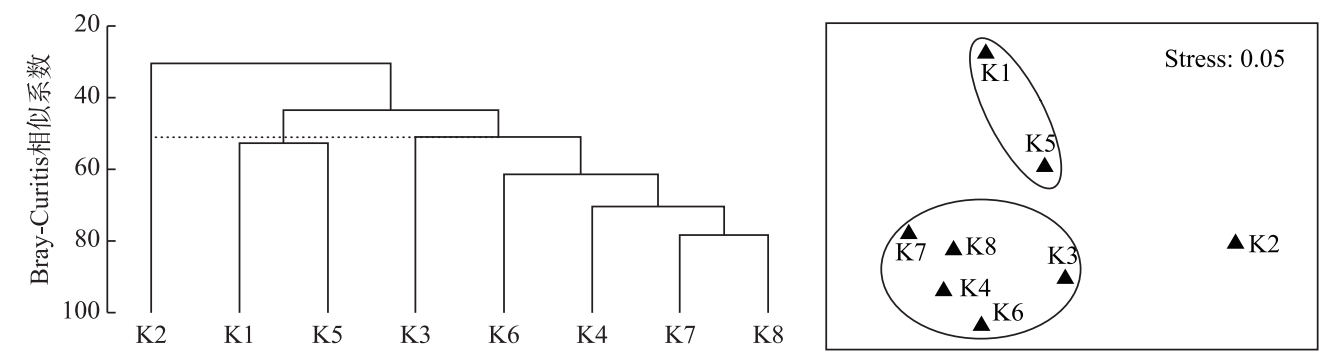

图 38 座典型水库聚类和多维尺度转换排序图

Fig.3 The cluster and multidimensional scaling of eight main reservoirs

\section{6 浮游植物与环境因子之间的相关性}

对浮游植物密度与环境因子进行 Spearman 相关性 分析, 发现浮游植物密度与 TN 和 Spc 呈极显著正相关 关系 $(P<0.01)$, 相关系数分别为 0.57 和 0.53 , 与海拔呈 极显著负相关 $(P<0.01)$, 相关系数为 -0.50 . 此外, 浮游 植物密度也与 $\mathrm{Sal}_{1} \mathrm{PO}_{4}^{3-}-\mathrm{P}$ 浓度和 $\mathrm{pH}$ 等呈显著正相关, 与 $\mathrm{NO}_{3}^{-}-\mathrm{N}$ 和 $\mathrm{DO}$ 呈显著负相关关系 $(P<0.05)$ (图 4).

运用典范对应分析对浮游植物与环境因子之间的 关系进行排序分析, 图 5 可以反映出 19 种优势种对环 境条件各自的适应特点. 第一排序轴与 $\mathrm{pH}(0.76)$ 和 $\operatorname{Spc}(0.82)$ 呈正相关, 与海拔呈负相关 $(-0.98)$; 第二排 序轴与 $\mathrm{DO}$ 浓度 $(0.80)$ 和 $\mathrm{NO}_{3}^{-}-\mathrm{N}$ 浓度 $(0.73)$ 均呈正相 关, 与 $\mathrm{TN}$ 浓度 $(-0.97)$ 和 $\mathrm{T}(-0.80)$ 均呈负相关. 根据 各环境因子的分布特征, 将 19 种浮游植物归为 4 组. 其中组 1 包括细小平裂藻、史密斯微囊藻和惠氏微囊 藻, 与 TN 浓度和温度呈正相关; 组 2 包括微小曲壳藻、 延长等片藻细弱变种、等片藻和扇形藻, 与海拔呈正相

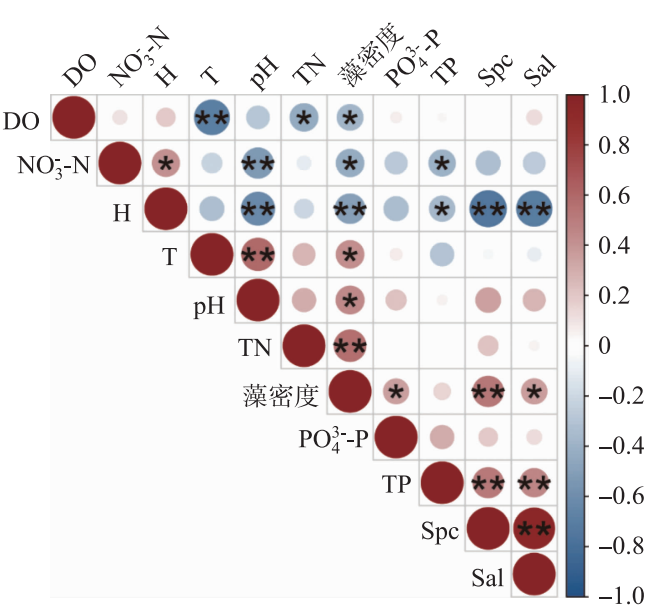

图 4 浮游植物总密度与 环境因子的 Spearman 相关性分析

Fig.4 Spearman correlation analysis of total phytoplankton density and environmental factors 关关系; 组 3 包括分歧雉囊藻、飞燕角甲藻、尖针杆藻、 尖端菱形藻和谷皮菱形藻等物种, 其分布与 $\mathrm{DO}$ 和 $\mathrm{NO}_{3}^{-}-\mathrm{N}$ 浓度均呈正相关, 与 $\mathrm{T}$ 和 $\mathrm{pH}$ 均呈负相关; 组 4 主 要包括蓝藻门的席藻、束丝藻、棒胶藻和假鱼腥藻及绿藻门的四尾栅藻和球衣藻, 主要与 $\mathrm{Spc} 、 \mathrm{TP}$ 及 $\mathrm{PO}_{4}^{3-}-\mathrm{P}$ 浓度呈正相关, 与海拔呈负相关关系.

\section{3 讨论}

水体中浮游植物群落结构和动态是多个环境因子在时空序列上综合作用的结果 ${ }^{[25]}$, 一般而言, 浮游植 物随季节变化呈现一定的演替规律, 即春、冬季硅藻和金藻为主, 夏、秋季蓝藻和绿藻占优, 而冬季浮游植物 种类数和密度均较低 ${ }^{[17]}, \mathrm{K} 2$ 水库全年硅藻占优除外, 其余 7 座水库演替规律一致. Stomp 等对美国 540 个湖 泊调查发现, 地理格局及海拔对浮游植物多样性及丰度产生显著影响 ${ }^{[26]}$. 然而, 水库受人为水位调度和污 染物排放等影响, 浮游植物群落的演替亦会发生显著改变 ${ }^{[27-28]} .2017$ 年度, 对西北干旱气候区 8 座典型水库 进行调查, 共计检出浮游植物 8 门 106 属 294 种, 以硅藻门、绿藻门和蓝藻门种类为主 (占比分别为 $48.35 \%$ 、 $26.64 \%$ 和 $14.47 \%)$, 浮游植物种类及密度随季节和空间地理分布呈现显著差异 $(P<0.05)$. 聚类和 nMDS 分 析结果表明, 8 座水库主要分为 3 组, 其中处于祁连山区高海拔的海潮坝水库 (K2) 独立一组, 水库水源主要 


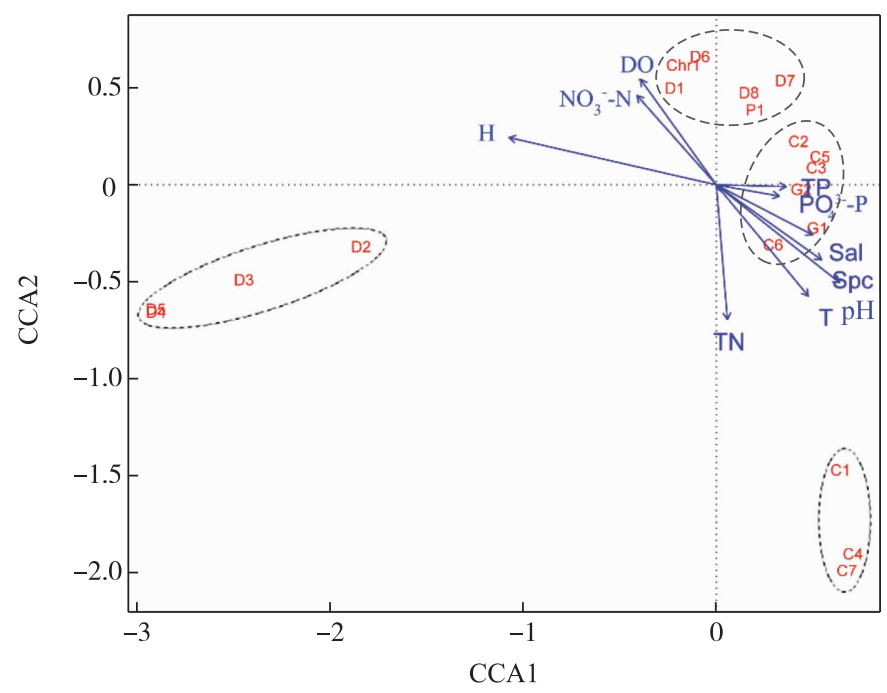

图 5 主要优势种与环境因子之间的典范对应分析 (C1 席藻 (Phormidium sp.), C2 细小平裂藻

(Merismopedia minima), C3 束丝藻(Aphanizomenon sp.), C4 史密斯微囊藻 (Microcystis smithii), C5 棒胶藻 (Rhabdogloea sp.), C6 假鱼腥藻 (Pseudanabaena sp.), C7 惠氏微囊藻 (Microcystis wesenbergii), G1 四尾栅藻 (Scenedesmus quadricauda), G2 球衣藻 (Chlamydomonas globosa), D1 舟形藻 (Navicula sp.),

D2 微小曲壳藻 (A. minutissima), D3 延长等片藻细弱变种 (Daitoma elongatum var. tenuis),

D4 等片藻 (Diatoma sp.), D5 扇形藻 (Meridium sp.), D6 尖针杆藻 (Synedra acus),

D7 尖端菱形藻 (Nitzschia acula), D8 谷皮菱形藻 (Nitzschia palea)，

P1 飞燕角甲藻 (Ceratium hirundinella), Chr1 分歧雉囊藻 (Dinobryon divergens))

Fig.5 CCA biplot of dominant phytoplankton species and environmental factors

来自高山冰雪融水, 浮游植物主要以喜低温和贫营养环境的硅藻如微小曲壳藻、延长等片藻细弱变种和扇 形藻等为主要优势种; 其次, 李桥水库 (K1) 和马郡滩水库 (K5) 主要以分歧雉囊藻、飞燕角甲藻、尖针杆藻和 谷皮菱形藻等物种为主要优势种而聚为一组; 其余 5 座水库聚为一组, 其中刘家深湖水库 (K6)、马尾湖水库 (K7) 和天城水库 (K8) 水库位于黑河张掖段下游, 承载了黑河及周围农田面源污染汇人的氮、磷等营养物 质, 尤其在夏、秋季高水温环境中蓝藻门种类快速繁殖并占据明显优势, 而 K4 受渔业养殖的影响, 水体富营 养化程度高.

浮游植物多样性指数的变化能够直观地评判水体营养状况及其对浮游植物群落结构所产生的影响 ${ }^{[29]}$, 水体受到污染越严重时, 浮游植物多样性指数值越小 ${ }^{[30]} .2017$ 年张掖 8 座水库 Shannon-Wiener 指数、 Simpson 指数、Pielou 均匀度指数和 Margalef 指数年均值分别为 $2.26 、 0.77 、 1.20$ 和 0.86 , 可知水库属 $\beta$ 中污 型. 然而, 浮游植物多样性与水质关系较复杂, 易受水体类型、计数方法和鉴定种类的影响 ${ }^{[31]}$, 因此, 再结合 况琪军等 ${ }^{[29]}$ 利用浮游植物细胞密度和物种组成对水质的评价标准, 由于李桥水库 (K1)、海潮坝水库 (K2)、 鹦鸽嘴水库 (K3) 和马郡滩水库 (K5) 浮游植物密度年均值小于 $10^{6} \mathrm{cells} / \mathrm{L}$, 且群落结构主要以硅藻、甲藻和 金藻门种类为主, 因此可判定上述水体为贫营养; 而其余 4 座水库藻密度年均值都大于 $10^{6} \mathrm{cells} / \mathrm{L}$ (刘家深 湖水库和马尾湖水库超过 $10^{7} \mathrm{cells} / \mathrm{L}$ ), 同时浮游植物以蓝藻、绿藻占优, 因而判定水体为中营养一中富营养.

水体营养盐和物理因子可直接影响浮游植物的物种组成、数量及分布等, 普遍认为水体充足的氮、磷和 适宜的光、温条件促使藻类大量增殖 ${ }^{[22-33]}$. 然而, 气候因子、地理格局及土地利用类型对浮游植物分布的影 响亦不容忽视 ${ }^{[34-35]}$. 张掖位于祁连山南部, 境内包括祁连山山区、中部绿洲农业区和北部盐碱地一荒漠区, 此 外, 该地区年蒸发量高 $\left(2047 \mathrm{~mm}\right.$ ), 干旱指数达 $15.97^{[36]}$, 导致水体环境因子呈现明显的时空趋异特征 ${ }^{[37]}$, 尤其黑河下游水库盐度的增加更为显著. 自然水体中, 盐度是影响浮游植物组成的关键因子 ${ }^{[38]}$, 盐度增加 会促使蓝藻门种类逐渐占据优势 ${ }^{[39]}$. 本研究发现类似结果, 即随着水库水体盐度的升高, 蓝藻门种类物种 
数量及密度均明显增加, 并占据优势. 先前研究结果显示, 海拔、温度及高盐度是影响黑河张掖段浮游植物 群落的主要环境因子, 同时中游绿洲农业区及城市富集的高氮、磷营养盐亦是关键影响因素 ${ }^{[40]}$. 本研究针 对浮游植物及环境因子的 Spearman 相关性分析结果表明, TN、Spc、Sal、温度和海拔亦是影响水库浮游植物 密度的主要因素. 研究表明, 不同区域水体中影响浮游植物的环境因子并不一致, 氮、磷营养盐、溶解氧、温 度及人为干扰都会主导浮游植物呈现不同集群的分布 ${ }^{[41]}$; 此外, 长期适应高海拔区域极端环境的游植物群 落也具有其明显的特征 ${ }^{[42]}$. CCA 排序能够很好地解释物种与环境因子之间的内在联系, 也能反映出不同物 种的生态分化现象 ${ }^{[43]}$. 本研究 $\mathrm{CCA}$ 结果显示, 海拔、温度、 $\mathrm{Spc} 、 \mathrm{TN}$ 及 $\mathrm{NO}_{3}^{-}-\mathrm{N}$ 浓度是影响优势种分布的主要 环境因子. 其中微小曲壳藻、延长等片藻细弱变种、等片藻和扇形藻是仅有的与海拔呈正相关关系的一组, 其主要分布在祁连山区的海潮坝水库 (K2) ; 同时, 分歧雉囊藻、飞燕角甲藻、尖针杆藻、尖端菱形藻和谷皮菱 形藻等物种与 $\mathrm{DO}$ 和 $\mathrm{NO}_{3}^{-}-\mathrm{N}$ 浓度均呈正相关, 与 $\mathrm{T}$ 和 $\mathrm{pH}$ 均呈负相关. 研究表明, 高氮、磷营养盐含量和水温 的升高诱导水华蓝藻大量增殖 ${ }^{[44-45]}$, 本研究发现类似结果, 即刘家深湖水库 (K6)、马尾湖水库 (K7) 和天城 水库 (K8) 水华蓝藻细小平裂藻、史密斯微囊藻和惠氏微囊藻与 TN 和温度呈正相关, 丝状蓝藻席藻、束丝 藻、棒胶藻和假鱼腥藻与 $\mathrm{Spc} 、 \mathrm{TP}$ 及 $\mathrm{PO}_{4}^{3-}-\mathrm{P}$ 浓度均呈正相关, 尤其史密斯微囊藻密度在夏季超过水华阈值 ( $10^{7}$ cells $\left./ \mathrm{L}\right)$,值得引起注意.

\section{4 结论}

1) 2017 年张掖 8 座典型水库共计检出浮游植物 8 门 106 属 294 种, 以硅藻门、绿藻门和蓝藻门种类为 主, 占比分别为 $48.35 \%$ 、26.64\% 和 $14.47 \%$, 浮游植物种类及密度随季节和空间地理分布呈现显著差异 $(P<$ $0.05)$.

2) 聚类和 nMDS 分析结果表明,8 座典型水库主要分为 3 组,其中高海拔区域的海潮坝水库 (K2) 独立 一组, 以喜低温和贫营养环境的硅藻为主要优势种; 第二组为较高海拔区域李桥水库 (K1) 和鹦鸽嘴水库 (K5), 以分歧雉囊藻和谷皮菱形藻、尖针杆藻等为主要优势种; 其余 5 座富营养化程度相对较高的水库聚为 一组,尤其在夏、秋季,蓝藻门种类占据优势明显.

3) Spearman 相关性分析和 CCA 分析发现, TN、Spc、T 和海拔是水库浮游植物密度大小及优势种分布的 主要影响因子, 低海拔区域水库中细小平裂藻、史密斯微囊藻和惠氏微囊藻等水华蓝藻随着水温升高而占 据绝对优势, 尤其史密斯微囊藻密度在夏季超过水华國值 $\left(10^{7}\right.$ cells $\left./ \mathrm{L}\right)$, 值得引起注意.

致谢: 感谢中国科学院海洋研究所徐沙博士对本文写作的帮助.

\section{5 参考文献}

[ 1 ] Han BP. Reservoir ecology and limnology in China: a retrospective comment. J Lake Sci, 2010, 22(2) : 151-160. DOI: 10.18307/2010.0201. [韩博平. 中国水库生态学研究的回顾与展望. 湖泊科学, 2010, 22(2): 151-160.]

[ 2 ] Lin WP, Peng B. Effect of world reservoir on surrounding environment. Environmental Science, 1987, 8(2) : 91-95, 34. DOI : 10.13227/j.hjkx.1987.02.027. [林文盘, 彭斌. 世界水库对周围环境的影响. 环境科学, 1987, 8(2): 9195,34 . ]

[ 3 ] Zhang YM. Advance on aquaculture and propagation technology of lake and reservior in China. Journal of Fisheries of Chi$n a, 1992,16(2)$ : 179-187. [张幼敏. 中国湖泊、水库水产增养殖技术的进展. 水产学报, 1992, 16(2): 179-187.]

[ 4 ] Straskraba M. The application of predictive mathematical models of reservoir ecology and water quality. Canadian Water Resources Journal, 1982, 7(1) : 283-318. DOI: 10.4296/cwrj0701283.

[ 5 ] Wehr JD, Sheath RG, Kociolek JP. Freshwater algae of North America. Amsterdam: Elsevier, 2015.

[ 6 ] Han BP, Armengol J, Garcia JC et al. The thermal structure of Sau Reservoir ( NE: Spain) simulation approach. Ecological Modelling, 2000, 125(2/3): 109-122.

[ 7 ] Lv H, Yang J, Liu LM et al. Temperature and nutrients are significant drivers of seasonal shift in phytoplankton community from a drinking water reservoir, subtropical China. Environmental Science and Pollution Research, 2014, 21(9) : 59175928. DOI: $10.1007 / \mathrm{s} 11356-014-2534-3$.

[ 8 ] Zhang Y, Ma XF, Guo FF et al. Community structures of phytoplankton and their relationships with environmental factors in the Jinshahe Reservoir, Hubei Province. J Lake Sci, 2015, 27( 5) : 902-910. DOI: 10.18307/2015.0517. [张云, 马 
徐发, 郭飞飞等. 湖北金沙河水库浮游植物群落结构及其与水环境因子的关系. 湖泊科学, 2015, 27(5): 902-910.]

[ 9 ] Wang YH, Chen L, Niu Y et al. Spatio-temporal variation in phytoplankton community and its influencing factors in Danjiangkou Reservoir. J Lake Sci, 2016, 28(5) : 1057-1065. DOI: 10.18307/2016.0516. [王英华, 陈雷, 牛远等. 丹江 口水库浮游植物时空变化特征. 湖泊科学, 2016, 28(5): 1057-1065.]

[10] Du GS, Meng FY, Li XD et al. Water quality and development trend of Miyun Reservoir. Environmental Science, 1999,20 (2) : 111-113. [杜桂森, 孟繁艳, 李学东等. 密云水库水质现状及发展趋势. 环境科学, 1999, 20(2): 111-113.]

[11] Kuo JT, Hsieh MH, Lung WS et al. Using artificial neural network for reservoir eutrophication prediction. Ecological Modelling, 2007, 200(1/2) : 171-177. DOI: 10.1016/j.ecolmodel.2006.06.018.

[12] Zhao MX, Han BP. Analysis of factors affecting cyanobacteria bloom in a tropical reservoir (Tangxi Reservoir, China). Acta Ecologica Sinica, 2005, 25(7): 1554-1561. [赵孟绪, 韩博平. 汤溪水库蓝藻水华发生的影响因子分析. 生态学 报, 2005, 25(7): 1554-1561.]

[13] Zeng H, Song LR, Yu ZG et al. Preliminary study on algal blooms within the Three Gorges Reservoir. Resources and Environment in the Yangtze Basin, 2007, 16(3):336-339. [曾辉, 宋立荣, 于志刚等. 三峡水库“水华”成因初探. 长江流 域资源与环境, 2007, 16(3):336-339.]

[14] Chen W, Song LR, Gan NQ et al. Sorption, degradation and mobility of microcystins in Chinese agriculture soils: Risk assessment for groundwater protection. Environmental Pollution, 2006, 144 (3) : 752-758. DOI: 10.1016/j. envpol.2006. 02.023 .

[15] Xie P. A review on the studies related to the effects of microcystins on human health. J Lake Sci, 2009, 21(5): 603-613. DOI: 10.18307/2009.0501. [谢平. 微囊藻毒素对人类健康影响相关研究的回顾. 湖泊科学, 2009, 21 (5): 603-613.]

[16] Li JB, Liu CP, Wang KL et al. Estimation of economic value of large reservoirs ecosystem services in Hunan Province. Journal of Soil and Water Conservation, 2005, 19(2): 163-166. [李景保, 刘春平, 王克林等. 湖南省大型水库服务 功能的经济价值评估. 水土保持学报, 2005, 19(2): 163-166.]

[17] Hu HJ, Wei YX eds. The freshwater algae of China: Systematics, taxonomy and ecology. Beijing: Science Press, 2006. [胡鸿钧, 魏印心. 中国淡水藻类——系统, 分类及生态. 北京: 科学出版社, 2006.]

[18］Zhu HZ, Chen JY eds. Bacillariophyta of the Xizang Plateau. Beijing: Science Press, 2000. [朱蕙忠, 陈嘉佑. 中国西 藏硅藻. 北京: 科学出版社, 2000.]

[19] Wu ZX, Yu GL, Shi JQ et al. The two newly recorded species of bloom-forming cyanobacterial genus Aphanizomenon Morr. Ex Born. Et Flah. (Cyanophyta) from China. Acta Hydrobiologica Sinica, 2009, 33(6) : 1140-1144. [吴忠兴, 虞功亮, 施军琼等. 我国淡水水华蓝藻——束丝藻属新记录种. 水生生物学报, 2009, 33(6): 1140-1144.]

[20] You QM. Studies on Aulonoraphidinales (Bacillariophyta) of freshwater in China [Dissertation]. Shanghai: East China Normal University, 2009. [尤庆敏. 中国淡水管壳缝目硅藻的分类学研究 [学位论文]. 上海: 华东师范大 学, 2009.]

[21] Editorial Board of Water and Wastewater Monitoring and Analysis Methods, Ministry of Environmental Protection of the People's Republic of China eds. Water and Wastewater Monitoring and Analysis Methods: 4th edition. Beijing: China Environmental Science Press, 2002. [国家环境保护总局《水和废水监测分析方法》编委会. 水和废水监测分析方法: 第 4 版. 北京: 中国环境科学出版社, 2002.]

[22] Lampitt RS, Wishner KF, Turley CM et al. Marine snow studies in the Northeast Atlantic Ocean: Distribution, composition and role as a food source for migrating plankton. Marine Biology, 1993, 116 ( 4): 689-702. DOI: 10. 1007/BF00355486.

[23] Lopes MRM, Bicudo CEM, Ferragut MC. Short term spatial and temporal variation of phytoplankton in a shallow tropical oligotrophic reservoir, southeast Brazil//Aquatic Biodiversity II. Dordrecht: Springer, 2005: 235-247.

[24] Flores LN, Barone R. Phytoplankton dynamics in two reservoirs with different trophic state (Lake Rosamarina and Lake Arancio, Sicily, Italy)//Phytoplankton and trophic gradients. Dordrecht: Springer, 1998: 163-178.

[25] Reynolds CS. What factors influence the species composition of phytoplankton in lakes of different trophic status? Hydrobiologia, 1998, 369/370: 11-26.

[26] Stomp M, Huisman J, Mittelbach GG et al. Large-scale biodiversity patterns in freshwater phytoplankton. Ecology, 2011, 92(11) : 2096-2107. DOI: 10.1890/10-1023.1. 
[27] Ma PM, Shi LD, Zhang JF et al. Succession of phytoplankton assemblages and its influencing factors in Tangpu reservoir, Zhejiang Province. Environmental Science, 2016, 37(12) : 4560-4569. [马沛明, 施练东, 张俊芳等. 浙江汤浦水库浮 游植物季节演替及其影响因子分析. 环境科学, 2016, 37(12) : 4560-4569.]

[28] Da WY, Zhu GW, Wu ZX et al. Long-term variation of phytoplankton community and driving factors in Qiandaohu Reservoir, southeast China. J Lake Sci, 2019, 31(5): 1320-1333. DOI: 10.18307/2019.0522. [笪文怡, 朱广伟, 吴志旭 等. 2002-2017 年千岛湖浮游植物群落结构变化及其影响因素. 湖泊科学, 2019, 31(5): 1320-1333.]

[29] Kuang QJ, Ma PM, Hu ZY et al. Study on the evaluation and treatment of lake eutrophication by means of algae biology. Journal of Safety and Environment, 2005, 5(2): 87-91. [况琪军, 马沛明, 胡征宇等. 湖泊富营养化的藻类生物学 评价与治理研究进展. 安全与环境学报, 2005, 5(2) : 87-91.]

[30] Telesh IV. Plankton of the Baltic estuarine ecosystems with emphasis on Neva Estuary: A review of present knowledge and research perspectives. Marine Pollution Bulletin, 2004, 49(3) : 206-219. DOI: 10.1016/j.marpolbul.2004.02.009.

[31] Sun J, Liu DY. The application of diversity indices in marine phytoplankton studies. Acta Oceanologica Sinica, 2004,26 (1) : 62-75. [孙军, 刘东艳. 多样性指数在海洋浮游植物研究中的应用. 海洋学报: 中文版, 2004, 26 (1) : 62-75.]

[32] Xu H, Paerl HW, Qin BQ et al. Nitrogen and phosphorus inputs control phytoplankton growth in eutrophic Lake Taihu, China. Limnology and Oceanography, 2010, 55(1) : 420-432. DOI: 10.4319/lo.2010.55.1.0420.

[33] Kunlasak K, Chitmanat C, Whangchai N et al. Relationships of dissolved oxygen with chlorophyll-a and phytoplankton composition in tilapia ponds. International Journal of Geosciences, 2013, 4(5) : 46-53. DOI: 10.4236/ijg.2013.45B008.

[34] Santos JBO, Silva LHS, Branco CWC et al. The roles of environmental conditions and geographical distances on the species turnover of the whole phytoplankton and zooplankton communities and their subsets in tropical reservoirs. Hydrobiologia, 2016, 764(1) : 171-186. DOI: 10.1007/s10750-015-2296-z.

[35] Beaver JR, Scotese KC, Minerovic AD et al. Land use patterns, ecoregion and phytoplankton relationships in productive Ohio reservoirs. Inland Waters, 2012, 2(2) : 101-108. DOI: 10.5268/IW-2.2.481.

[36] Kong DS, Zhang H. Evaluation on the value of carbon sequestration function in the Heihe wetland national nature reserve in Zhangye. Wetland Science, 2014, 12(1) : 29-34. [孔东升, 张影. 张掖黑河湿地国家级自然保护区固碳价值评估. 湿地科学, 2014, 12(1): 29-34.]

[37] Hao YY, Sun GJ, Zhang LX et al. Relationship between community characteristics of the phytoplankton and environmental factors in Heihe River basin. J Lake Sci, 2014, 26(1) : 121-130. DOI: 10.18307/2014.0115. [郝媛媛, 孙国钧, 张立 勋等. 黑河流域浮游植物群落特征与环境因子的关系. 湖泊科学, 2014, 26(1): 121-130.]

[38] Pilkaitytë R, Schoor A, Schubert H. Response of phytoplankton communities to salinity changes—a mesocosm approach. Hydrobiologia, 2004, 513(1/2/3) : 27-38. DOI: 10.1023/B:hydr.0000018162.50270.54.

[39] Chakraborty P, Acharyya T, Raghunadh Babu PV et al. Impact of salinity and pH on phytoplankton communities in a tropical freshwater system: An investigation with pigment analysis by HPLC. Journal of Environmental Monitoring, 2011, 13 (3) : 614-620.

[40] Yang SQ, Zu TX, Wang HB et al. Relationship between the structure of phytoplankton community and environmental factors in the Zhangye section of Heihe River. J Lake Sci, 2019, 31(1) : 159-170. DOI: 10.18307/2019.0115. [杨宋琪, 祖廷勋, 王怀斌等. 黑河张掖段浮游植物群落结构及其与环境因子的关系. 湖泊科学, 2019, 31(1): 159-170.]

[41] Naselli-Flores L. Phytoplankton assemblages in twenty-one Sicilian reservoirs: Relationships between species composition and environmental factors. Hydrobiologia, 2000, 424(1/2/3): 1-11. DOI: 10.1023/ A : 1003907124528.

[42] Battarbee RW, Kernan M, Rose N. Threatened and stressed mountain lakes of Europe: Assessment and progress. Aquatic Ecosystem Health \& Management, 2009, 12(2) : 118-128. DOI: 10.1080/14634980902905742.

[43] Luan QS, Sun J, Song SQ et al. Canonical correspondence analysis of summer phytoplankton community and its environment in the Yangtze River estuary, China. Journal of Plant Ecology: Chinese Version, 2007, 31(3) : 445-450. [亱青杉, 孙军, 宋书群等. 长江口夏季浮游植物群落与环境因子的典范对应分析. 植物生态学报, 2007, 31(3): 445-450.]

[44] Kong FX, Gao G. Hypothesis on cyanobacteria bloom-forming mechanism in large shallow eutrophic lakes. Acta Ecologica Sinica, 2005, 25(3) : 589-595. [ 孔繁翔, 高光. 大型浅水富营养化湖泊中蓝藻水华形成机理的思考. 生态学报, $2005,25(3): 589-595$.

[45] Robarts RD, Zohary T. Temperature effects on photosynthetic capacity, respiration, and growth rates of bloom-forming cyanobacteria. New Zealand Journal of Marine and Freshwater Research, 1987, 21(3) : 391-399. 